\title{
The Neuropathological and Biological Impacts of Alzheimer's Disease on Spatial Memory: A Literature Review
}

\author{
Bridget H.M. Young, BMSc Student [1]
}

[1] Department of Science, University of Western Ontario, London, Ontario, Canada, N6A 3K7

*Corresponding Author: byoung65@uwo.ca

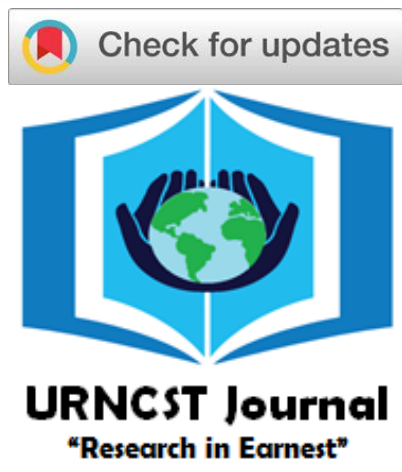

\begin{abstract}
Introduction: The effects of spatial memory on Alzheimer's disease (AD) pose a great hazard to the emotional and physical wellbeing of the patient and their families, affecting more than $60 \%$ of individuals with AD. This review explores the neuropathological and biological foundations of spatial memory with relation to AD.

Methods: The results in the 11 papers ( 7 animal studies, 4 clinical studies) will be described, examined, and compared with each other, and attempt to pinpoint areas for future research.

Results: Results from animal studies showed that neurotransmitter function, protein function, and calcium regulation are all impaired by $\mathrm{AD}$, which lowers the spatial memory and cognition in animals. In clinical studies, it was found that the medial temporal lobe (MTL) regions, including the hippocampus, amygdala, and entorhinal cortex, are compromised by AD and relate to spatial memory performance.

Discussion: This review concluded that more clinical research should be conducted around spatial memory, and animal research can explore the role of protein function given the relevance of neuropathology in AD.

Conclusion: With the information collected in this review, future steps can be taken to explore the intricacies of spatial memory and AD. Moreover, this review also poses a useful reference for other researchers examining the relation between spatial memory and AD.
\end{abstract}

Keywords: alzheimer's disease; biology; neuropathology; spatial memory; neurotransmitters; proteins; proteomics

\section{Introduction}

Alzheimer's disease (AD) is a chronic neurodegenerative disease that usually formulates in individuals above the age of 65 and is known as the most common cause of dementia [1]. According to a study in 2017 conducted by the Public Health Agency of Canada, over 400,000 older adults are diagnosed with dementia, including Alzheimer's disease [1]. Common impairments that individuals with $\mathrm{AD}$ experience include memory loss, inability to focus or reason, alterations in mood and social behaviour, and much more [2]. Given the large-scale prevalence of the disease, many studies have sought to understand the biological and neurological bases for $\mathrm{AD}$, as well as prevention methods and possible cures. While the latter goals have yet to yield certified results, many different studies have explored the neuropathologic foundations for the disease. Two of the major determinants of $\mathrm{AD}$ are amyloid plaques composed of 42-amino acid $\beta$ amyloid protein $(\mathrm{A} \beta 42)$, and intraneuronal neurofibrillary tangles which are composed of the microtubule-associated protein tau [3]. The brain structures that are largely impacted by $\mathrm{AD}$ include the hippocampus found in the medial temporal lobe (MTL) and other temporal lobe regions [4]. However, studies that investigate the areas of the brain affected by $\mathrm{AD}$ also consider that certain brain structures undergo neurodegeneration due to other factors like aging. This is because these brain structures, such as the frontoparietal regions, may be equally damaged by both aging or $\mathrm{AD}$ [4]. It should also be considered that many workings of the brain are interconnected, relying on various structures of the brain for cognition and behaviour.

While individuals with early $\mathrm{AD}$ may only experience mild symptoms, severe cases of the disease can prevent individuals from progressing through day-to-day life, thus requiring extensive care; in such instances, the situation can lead to a decline in quality of life of both these individuals and their families [2]. One particular symptom of AD is an impairment of spatial memory: The ability to remember information about a particular space, its layout, and locations, as well as their orientation [5]. Spatial memory impairment occurs in more than $60 \%$ of the $\mathrm{AD}$ population [6]. This cognitive ability can be measured by certain spatial-related tasks, such as memorizing object location, recognizing object rotation, and understanding perspective with maps that cannot be rotated [5]. One noteworthy example is the Corsi block-tapping test in which the 
UNDERGRADUATE RESEARCH IN NATURAL AND CLINICAL SCIENCE AND TECHNOLOGY (URNCST) JOURNAL Read more URNCST Journal articles and submit your own today at: https://www.urncst.com

participant taps cubes on a screen based on a novel sequence of increasing length [7]. Spatial memory is largely supported by the hippocampal region, which plays a major role in memory; damage to the hippocampus structure is associated with memory impairment, such as declarative memory (recalling facts or information), episodic memory, and notably spatial memory [8]. Individuals with spatial memory impairment are seen to exhibit wandering behaviour, compromised spatial navigation abilities, and feeling lost in new and familiar environments [9]. Although commonly heralded as a major hallmark of the disease, research on the impact of $\mathrm{AD}$ on spatial memory is still developing.

This review seeks to explore the biological and neurological foundations for the impact of $\mathrm{AD}$ on spatial memory, highlighting the main brain structures involved and affected in this situation. This review also sets out to evaluate the findings of current studies on spatial memory, comparing and contrasting conclusions when relevant. Evaluating the role of relevant areas of the brain on spatial memory can further new frontiers for directions in research. By understanding more about these correlations, steps can be taken to explore neurological contributions to $\mathrm{AD}$ and focus on prevention and treatment. Furthermore, evaluating information can provide a helpful reference for others pursuing research on similar topics.

\section{Methods}

To systematically determine the brain structures that contribute to spatial memory loss in $\mathrm{AD}$, studies were collected using electronic databases, including the Western Libraries Database and Google Scholar. All papers included were published within the past two decades, peer-reviewed, and were independent studies. All clinical studies included both participants with healthy controls and patients with AD. The studies chosen were categorized into either animal-based studies (e.g., rat studies) or clinical studies. 11 studies were reviewed in total, comprised of 7 animal studies and 4 clinical studies. Studies focusing on similar topics were compared and examined for supporting or contrasting conclusions. These fields of research will be separated in an attempt to standardize the information collected to be validly compared.

\section{Results}

Animal Studies

\section{Neurotransmitter Function}

Multiple studies have directed their attention towards neurotransmitter function and decreases in spatial memory due to AD. In 2017, Zhu and colleagues conducted a study on rats to determine the effects of $\mathrm{AD}$ on spatial memory with direct relation to the hippocampus and cholinergic synapses. The study posed different challenges to the mice, including a touch screen test (for spatial pattern separation) and the Morris water maze tests [10]. The study found that newly generated immature neurons (NGIs) in the dorsal hippocampus (dNGIs) are particularly associated with pattern-separation associated spatial memory [10]. It was also discovered that mice with $\mathrm{AD}$ had demonstrated a decrease of cholinergic synapses in dNGIs, which was also associated with the loss of spatial pattern separation in the mice. This was examined by staining mice with an antibody against the choline acetyltransferase (chAt) protein. It was found that the densities of the chAt-labelled terminals were $49 \%$ lower in AD mice than in controls $(\mathrm{p}<0.01)$ [10]. This suggests that acetylcholine (ACh), the neurotransmitter involved in cholinergic synapses, plays a role in maintaining spatial memory; therefore, impairment in cholinergic functioning may be a neurobiological mechanism underlying spatial memory deficits in AD [10]. Moreover, Mookherjee and colleagues studied the importance of glutamate on spatial memory with respect to $\mathrm{AD}$, focusing specifically on the glutamate transporter GLT-1. Glutamate is another neurotransmitter that mediates cognition, emotions, sensory information, and other neural processes. Using the Morris water maze to test spatial memory, the study focused on mice with GLT-1 and mice lacking one allele for GLT-1; results noticed a significant reduction in the ability to progress through the maze which was constant between groups $(p<0.001)[11]$. This points to the notion that glutamatergic signalling or function may also contribute to declines in spatial memory due to AD [11].

\section{Protein Function}

In addition to neurotransmitters, other studies in mice explored the importance of various protein functions on spatial memory. A study by Xing and colleagues focused on using two-dimensional fluorescence difference gel electrophoresis (2D-DIGE) and mass spectrophotometry, finding 23 differentially expressed proteins in the hippocampi of mice with a certain strain of $\mathrm{AD}, 3 \mathrm{XTg}-\mathrm{AD}$ [12]. The study concluded that two particular memoryassociated proteins, complexin 2 and tubulin alpha-1B, may have an underlying connection to spatial memory loss [12]. Another study by Kitamura and colleagues studied the protein deglycase (DJ-1) which is a chaperone protein commonly associated with Parkinson's disease. DJ-1's chaperone activity relates to beta-amyloid (A $\beta 42)$ aggregate formation, which is a highly toxic version of $A \beta$ that makes up amyloid beta plaques that are characteristic of AD [13]. The study tested for spatial memory through the Morris water maze both pre-treatment and post-treatment, concluding that DJ-1 modulators may help treat disorders like Parkinson's disease and AD by preventing DJ-1 from promoting A $\beta 42$ build-up [13]. Additionally, Burnham and colleagues noted the impact of luteinizing hormone (LH) in relation to the dorsal hippocampus through rat experiments. This experiment was predicated on the notion that $\mathrm{LH}$ increases during and after menopause, which has been correlated with an increased incidence of $\mathrm{AD}$ and decreased memory performance in humans and animal models [14]. In Burnham's study, ovariectomized female rats were infused 
UNDERGRADUATE RESEARCH IN NATURAL AND CLINICAL SCIENCE AND TECHNOLOGY (URNCST) JOURNAL Read more URNCST Journal articles and submit your own today at: https://www.urncst.com

with either the LH-homologue human chorionic gonadotropin (hCG) or the $\mathrm{LH}$ receptor antagonist deglycosylated-hCG (dg-hCG) [14]. Rats were either given estradiol capsules (E) which are said to maintain spatial memory retention, or blank control capsules (blk) containing no hormone. The rats were given a drug vehicle (veh) to help with administration of substances [14]. Moreover, to assess the spatial memory in rats, the Object Location Test (OLT) was used, where the rats were subjected to an exposure phase and retention phase separated by an intertrial interval. In the exposure phase, animals are introduced to the arena where two identical objects are present. After the intertrial interval, in the retention phase the rats are reintroduced to the arena, where one of the objects is moved in a different, novel location [14]. The OLT relies on the idea that a rat would explore the novel configuration longer than a familiar configuration, which suggests that the rat recognizes a novel configuration, implying that spatial memory is intact [14]. The main finding from the experiment showed that hippocampal infusion of an LH/CG-receptor antagonist enhanced spatial memory in rats $(p=0.0003)$ [14]. Therefore, the study concluded that higher serum LH levels are associated with decreased performance on cognitive tasks and specifically spatial memory in the rats tested. As a result of the findings, the study highlighted the possible importance of $\mathrm{LH}$ receptor antagonists in the dorsal hippocampus as a possible alleviator for decreased spatial memory [14].

These studies, which describe the connection between protein function and spatial memory, help provide a biological explanation for the decrease in spatial memory due to $\mathrm{AD}$. Finally, another biological hallmark of $\mathrm{AD}$ is the accumulation of tau in the brain. A study conducted by $\mathrm{Fu}$ and colleagues investigated the impact of tau pathology with spatial memory deficiency in mice [15]. The findings showed a great accumulation of tau in the hippocampal and parahippocampal regions in comparison to controls, finding a significant difference in spatial memory performance between mice with and without the presence of tau in the entorhinal cortex. The relation between tau accumulation and memory deficits was examined using Morris water maze and T-maze tests. The studies suggest a connection between tau build-up in the entorhinal cortex and the resulting deficit in spatial memory, emphasizing the role of the entorhinal cortex in navigation and spatial cognition [15].

\section{Calcium Regulation}

Finally, a study focusing on the $3 x \mathrm{Tg}$-AD mice model of AD facilitated a similar study to Zhu's on synaptic plasticity and calcium. The study led by Clark and colleagues tested mice with $\mathrm{AD}$ in an 8-arm radial maze in order to assess spatial working memory, finding that mice with $3 \mathrm{xTg}-\mathrm{AD}$ and non-Tg mice performed equally well in an 8-arm radial maze [16]. However, in another experiment where mice were tested in a different assay which depended on the mice's long-term working memory, the spatial working memory in $3 \mathrm{xTg}-\mathrm{AD}$ mice was impaired when they were also required to use long-term working memory [16]. To determine the significance of the results with related brain structures, electrophysiological recordings in hippocampal slices were taken. One phenomenon observed was paired-pulse facilitation (PPF), which refers to the short-term plasticity of the neurons; in other words, the ability for the neuron to help facilitate change in the neuronal network [17]. Changes in presynaptic calcium levels and calcium homeostasis are expected to affect PPF, given that calcium is a large actor in regulating neuron signalling. The results indicate a significant decrease in the PPF ratio within the hippocampus, which may indicate a relation between $\mathrm{AD}$ and dysregulation of calcium homeostasis [17]. This standalone study proposes that the biological basis for $\mathrm{AD}$ has roots in calcium homeostasis, which is fundamental to many biological systems across species.

\section{Clinical Studies}

A study conducted by Kessels and colleagues clinically measured spatial memory for object locations, highlighting the importance of the hippocampus in memory and cognition. The results showed that individuals with $\mathrm{AD}$ performed with more errors in relocating objects in a room than healthy controls $(p<0.03)$ [18]. Another study by Tuon and colleagues explored the impact of $\mathrm{AD}$ on the MTL regions, specifically the hippocampus, amygdala, and entorhinal cortex, with respect to spatial memory functions [19]. The study found that performance in a spatial orientation test was $46 \%$ lower in participants with $\mathrm{AD}$ than controls, comparing the results found with the incidence of lesions in the MTL [19]. The study suggests a connection between $\mathrm{AD}$ and MTL functioning.

Other studies explored and compared spatial memory impairment in amnestic mild cognitive impairment (aMCI) and $\mathrm{AD}$ in patients. Lee and colleagues conducted a study to examine spatial memory impairments in patients with either aMCI or $\mathrm{AD}$, using a virtual radial arm maze (VRAM) task [20]. The results over several trials indicated that spatial memory is more impaired in patients with $\mathrm{AD}$ than patients with aMCI. Lee and colleagues concluded that the VRAM results can be utilized as a marker of early AD development among patients with aMCI. Another study conducted by Moodley and colleagues applied the 4 Mountains Test (4MT) as an examination of spatial memory in healthy controls, patients with mild cognitive impairment (MCI) and mild AD. The patients with MCI were either marked with a cerebrospinal fluid (CSF) biomarker which was as an indicator of underlying $\mathrm{AD}$. Test performance greatly varied between biomarkerpositive and biomarker-negative subgroups $(p=0.001)$ [21]. The test results concluded that performance on the 4MT is impaired in patients with MCI who also contain CSF biomarker evidence of underlying AD [21]. Therefore, 
UNDERGRADUATE RESEARCH IN NATURAL AND CLINICAL SCIENCE AND TECHNOLOGY (URNCST) JOURNAL Read more URNCST Journal articles and submit your own today at: https://www.urncst.com

it was concluded that spatial memory was more impaired in patients with MCI and underlying AD biomarkers than MCI patients without AD biomarkers [21].

\section{Discussion}

The mentioned studies on rodents mainly concentrated on the neurobiological factors of $\mathrm{AD}$ on spatial memory, including neurotransmitters, proteins, and other chemical substances. Studies have supported the relationship between inhibited neurotransmitter function and effect of deregulation of protein function, which both decrease spatial memory functions. Some studies also have related findings to current knowledge in the field concerning the prevalence of beta-amyloid plaques and accumulation of tau. While the aforementioned studies on rodents varied in the target of focus (neurotransmitters versus proteins), both are formed by amino acids. Provided that two separate studies both found considerable effects on spatial memory due to $\mathrm{AD}$, future research can thus be benefited by directing attention to AD's connection to amino acid sequences. Moreover, the clinical studies focused on the effect of $\mathrm{AD}$ on relevant brain regions. The main conclusions note the correlation between $\mathrm{AD}$ and MTL regions, most specifically the hippocampus and entorhinal cortex. However, there is still a lack of clinical studies specifically measuring spatial memory in AD with links to brain structure and function. The paper encourages more clinical studies, especially to focus on the temporal lobe or parahippocampal gyrus. The main conclusion from the review suggests that the effects of $\mathrm{AD}$ are vast and affect the neurological system on both macroscopic and microscopic scales. The review has also recognized the importance of more studies with larger samples in a better effort to generalize findings and detect other overlooked observations. Even so, current studies have provided an adequate biological and neurological basis for future research to build upon.

\section{Limitations}

One of limitations of this review is the quantity of papers reviewed; given that only 11 papers were reviewed, comparisons and contrasting evidence were difficult to conduct since each study focused on various topics.

\section{Conclusions}

The review set out to outline the biological and neurological factors affected by $\mathrm{AD}$ in relation to spatial memory. Relevant animal studies discovered the role of various neurotransmitters, proteins, and chemicals involved in spatial memory and how they are impacted by AD. The reviewed clinical studies highlighted pertinent brain regions involved in spatial memory and how they are impacted by AD. Based on the findings described in this review, later studies can be undertaken to explore prevention and treatment with consideration of the disease's biological and neurological foundations. This review highlights the vast findings of different studies in an attempt to shine light on novel directions for future research.

\section{List of Abbreviations Used}

ACh: acetylcholine

AD: Alzheimer's disease

aMCI: amnestic mild cognitive impairment

A $\beta 42$ : 42 -amino acid $\beta$-amyloid protein

blk: blank control capsule

chAt: choline acetyltransferase

CSF: cerebrospinal fluid

dg-hCG: deglycosylated-hCG

DJ-1: deglycase

dNGI: newly generated immature neurons in the dorsal

hippocampus

E: estradiol capsule

hCG: chorionic gonadotropin

LH: luteinizing hormones

MCI: mild cognitive impairment

MTL: medial temporal lobe

NGI: newly generated immature neurons

OLT: Object Location Test

PPF: paired-pulse facilitation

veh: vehicle

VRAM: virtual radial arm maze

2D-DIGE: two-dimensional fluorescence difference gel

electrophoresis

4MT: 4 Mountains Test

\section{Conflicts of Interest}

The author declares that they have no conflicts of interest.

\section{Ethics Approval and/or Participant Consent}

This study did not require ethics approval and/or participant consent as it is a review of current literature.

\section{Authors' Contributions}

BY: made contributions to the design of the study, collected and analysed data, drafted the manuscript, and gave final approval of the version to be published.

\section{Acknowledgements}

I would like to thank Elly Wong for the help of editing and providing suggestions to the content of this paper.

\section{Funding}

This study was not funded.

\section{References}

[1] Dementia in Canada, Including Alzheimer's Disease. Public Health Agency of Canada; 2017. p. 1-5. Available from: https://www.canada.ca/en/publichealth/services/publications/diseasesconditions/dementia-highlights-canadian-chronicdisease-surveillance.html 
UNDERGRADUATE RESEARCH IN NATURAL AND CLINICAL SCIENCE AND TECHNOLOGY (URNCST) JOURNAL Read more URNCST Journal articles and submit your own today at: https://www.urncst.com

[2] Wong S L, Gilmour H, Ramage-Morin P L. Alzheimer's disease and other dementias in Canada. Ottawa (ON): Statistics Canada; 2016. p. 11-16. Available from: https://www150.statcan.gc.ca/n1/pub/82-003x/2016005/article/14613-eng.pdf

[3] Selkoe D. Preventing Alzheimer's Disease. Science. 2012; 337(6101), 1488-1492. https://doi.org/10.1126/ science. 1228541

[4] Bakkour A, Morris J C, Wolk D A, Dickerson B C. The effects of aging and Alzheimers disease on cerebral cortical anatomy: Specificity and differential relationships with cognition. NeuroImage. 2013; 76, 332-344. https://doi.org/10.1016/j.neuroimage.2013.02 .059

[5] Tascón L, Boccia M, Piccardi L, Cimadevilla J M. Differences in Spatial Memory Recognition Due to Cognitive Style. Frontiers in Pharmacology. 2017; 8, 550. https://doi.org/10.3389/fphar.2017.00550

[6] Jun H, Soma S, Saito T, Saido T C, Igarashi K M, Bramian A. Disrupted remapping of place cells and grid cells in knock-in model of Alzheimer's disease. Neuron. 2020 Sep 23; 107(6). https://doi.org/10.1016/ j.neuron.2020.06.023

[7] Guariglia C C. Spatial working memory in Alzheimers disease: A study using the Corsi block-tapping test. Dementia \& Neuropsychologia. 2007; 1(4), 392-395. https://doi.org/ 10.1590/s1980-57642008dn10400011

[8] Shrager Y, Bayley P J, Bontempi B, Hopkins R O, Squire L R. Spatial Memory and the Human Hippocampus. Proceedings of the National Academy of Sciences of the United States of America. 2007; 104 (8) 2961-2966. https://doi.org/10.1073/pnas.0611233 104

[9] Vlcek K. Spatial Navigation Impairment in Healthy Aging and Alzheimer's Disease. The Clinical Spectrum of Alzheimers Disease - The Charge Toward Comprehensive Diagnostic and Therapeutic Strategies. 2011 Sep 6. https://doi.org/10.5772/20278

[10]Zhu H, Yan H, Tang N, Li X, Pang P, Li H, Chan W, Guo Y, Shu S, Cai Y, Pei L, Dan L, Luo M, Man H, Tian Q, Mu Y, Zhu L, Lu, Y. Impairments of spatial memory in an Alzheimer's disease model via degeneration of hippocampal cholinergic synapses. Nature Communications. 2017 Nov 22; 8(1). https://doi.org/10.1038/s41467-017-01943-0

[11] Mookherjee P, Green P S, Cook D G. P1-099: Glutamate transporter dysfunction induces spatial memory deficits in a novel animal model of Alzheimers disease. Alzheimers \& Dementia. 2008 July; 4(4) 235236. https://doi.org/10.1016/j.jalz.2008.05.685

[12] Xing R, Sui X, Ying M, Liu J, Yang X. P2-040: Proteomic analysis on hippocampus in triple transgenic mice of Alzheimers disease: Implications in deciphering the key molecules involved in spatial memory impairment of early Alzheimers disease. Alzheimers \& Dementia. 2015 July 1; 11, 496-497.

https://doi.org/10.1039/c5tx00456j

[13] Kitamura Y, Inden M, Kimoto Y, Takata K, Yanagisawa D, Hijioka M, Ashihara E, Tooyama I, Shimohama S, Ariga H. Effects of a DJ-1-Binding Compound on Spatial Learning and Memory Impairment in a Mouse Model of Alzheimer's Disease. Journal of Alzheimers Disease. 2016 Sep; 55(1), 67-72. https://doi.org/10.1254/jpssuppl.wcp2018.0_po1-1-51

[14] Burnham V, Sundby C, Laman-Maharg A, Thornton J. Luteinizing hormone acts at the hippocampus to dampen spatial memory. Hormones and Behavior. 2017 Mar; 89, 55-63. https://doi.org/10.1016/j.yhbeh.2016.11.007

[15] Fu H, Rodriguez G A, Herman M, Emrani S, Nahmani E, Barrett G, Figueroa H Y, Goldberg E, Hussaini S A, Duff K E. Tau Pathology Induces Excitatory Neuron Loss, Grid Cell Dysfunction, and Spatial Memory Deficits Reminiscent of Early Alzheimer's Disease. Neuron. 2017 Feb 8; 93(3). https://doi.org/10.1016/ j.neuron.2016.12.023

[16] Clark J K, Furgerson M, Crystal J D, Fechheimer M, Furukawa R, Wagner J J. Alterations in synaptic plasticity coincide with deficits in spatial working memory in presymptomatic $3 \times \mathrm{Tg}-\mathrm{AD}$ mice. Neurobiology of Learning and Memory. 2015; 125, 152162. https://doi.org/10.1016/j.nlm.2015.09.003

[17] Dharani K. The Biology of Thought. $1^{\text {st }}$ ed. 2015. p. 53-74.

[18] Kessels R, Feijen J, Postma A. Implicit and Explicit Memory for Spatial Information in Alzheimer's Disease. Dementia and Geriatric Cognitive Disorders. 2005; 20(2-3), 184-191. https://doi.org/10.1159/ $\underline{000087233}$

[19] Tuon L, Portuguez M, Izquierdo I, Costa J C. A new spatial orientation memory test: Evaluation in patients with mild Alzheimers disease and in patients with operated and unoperated mesial temporal lobe epilepsy. The European Journal of Psychiatry. 2007 Jun; 21(2). https://doi.org/10.4321/s0213-61632007000 200005

[20] Lee J, Kho S, Yoo H B, Park S, Choi J, Kwon J S, Cha K R, Jung H. Spatial memory impairments in amnestic mild cognitive impairment in a virtual radial arm maze. Neuropsychiatric Disease and Treatment. 2014 Apr 17; 653. https://doi.org/10.2147/ndt.s58185

[21] Moodley K, Minati L, Contarino V, Prioni S, Wood R, Cooper R, D'Incerti L, Tagliavini F, Chan D. Diagnostic differentiation of mild cognitive impairment due to Alzheimers disease using a hippocampus-dependent test of spatial memory. Hippocampus. 2015 Aug; 25(8), 939951. https://doi.org/10.1002/hipo.22417 
UNDERGRADUATE RESEARCH IN NATURAL AND CLINICAL SCIENCE AND TECHNOLOGY (URNCST) JOURNAL

Read more URNCST Journal articles and submit your own today at: https://www.urncst.com

\section{Article Information}

Managing Editor: Jeremy Y. Ng

Peer Reviewers: Elly Wong, Ricky Chow

Article Dates: Received Apr 08 21; Accepted May 22 21; Published Jun 2821

\section{Citation}

Please cite this article as follows:

Young BHM. The neuropathological and biological impacts of alzheimer's disease on spatial memory: A literature review.

URNCST Journal. 2021 Jun 28: 5(6). https://urncst.com/index.php/urncst/article/view/269

DOI Link: https://doi.org/10.26685/urncst.269

\section{Copyright}

(C) Bridget H.M. Young. (2021). Published first in the Undergraduate Research in Natural and Clinical Science and Technology (URNCST) Journal. This is an open access article distributed under the terms of the Creative Commons Attribution License (https://creativecommons.org/licenses/by/4.0/), which permits unrestricted use, distribution, and reproduction in any medium, provided the original work, first published in the Undergraduate Research in Natural and Clinical Science and Technology (URNCST) Journal, is properly cited. The complete bibliographic information, a link to the original publication on http://www.urncst.com, as well as this copyright and license information must be included.

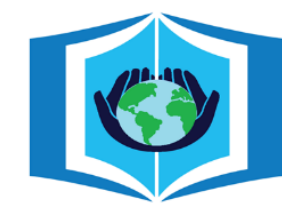

\section{URNCST Journal}

"Research in Earnest"

\section{Funded by the \\ Government \\ of Canada}

\section{Canadà̀}

Do you research in earnest? Submit your next undergraduate research article to the URNCST Journal!

|Open Access | Peer-Reviewed | Rapid Turnaround Time | International |

| Broad and Multidisciplinary | Indexed | Innovative | Social Media Promoted |

Pre-submission inquiries? Send us an email at info@ urncst.com |Facebook, Twitter and LinkedIn: @ URNCST

Submit YOUR manuscript today at https://www.urncst.com! 